Adela Dudić and Andreas Reiner*

\title{
Quinoxalinedione deprotonation is important for glutamate receptor binding
}

https://doi.org/10.1515/hsz-2018-0464

Received December 17, 2018; accepted March 15, 2019; previously published online March 23, 2019

Abstract: Quinoxalinediones are an important class of competitive antagonists at ionotropic glutamate receptors (iGluRs), where they are widely used to block $\alpha$-amino-3-hydroxy-5-methyl-4-isoxazolepropionic acid (AMPA) and kainate receptor responses. In this study we utilize two prototypic quinoxalinedione antagonists, namely DNQX and CNQX, which quench the intrinsic fluorescence of the ligand binding domain (LBD), to perform in vitro binding assays. We find that binding of DNQX and CNQX at the AMPA receptor GluA2 LBD is strongly $\mathrm{pH}$ dependent, whereas glutamate binding is not affected by $\mathrm{pH}$. We also show that the deprotonation of DNQX, CNQX and other quinoxalinediones (NBQX and YM90K) occurs close to physiological $\mathrm{pH}$, which can be explained by the lactam-lactim tautomerization of the quinoxalinedione scaffold. Analysis of our binding data indicates that quinoxalinedione deprotonation is a key requirement for binding, as we find a $>100$-fold higher affinity for binding of the monoanionic form compared to the neutral form. This suggests a large electrostatic contribution to the interaction with a conserved arginine residue located in the binding pocket of iGluRs. The strong $\mathrm{pH}$ dependence of quinoxalinedione binding, which has not previously been reported, is relevant for structure-function studies, but also for the use of quinoxalinediones in physiological experiments and envisioned therapeutic applications.

Keywords: amide-iminol tautomerism; energetic coupling; fluorescence binding assay; Förster resonance energy transfer (FRET); kainate receptor; ligand binding competition.

\footnotetext{
*Corresponding author: Andreas Reiner, Department of Biology and Biotechnology, Ruhr University Bochum, Universitätsstrasse 150, D-44801 Bochum, Germany, e-mail: andreas.reiner@rub.de Adela Dudić: Department of Biology and Biotechnology, Ruhr University Bochum, Universitätsstrasse 150, D-44801 Bochum, Germany
}

\section{Introduction}

Glutamate receptors are key signaling proteins in the central nervous system, which play important roles in synaptic function and disease. They encompass metabotropic glutamate receptors (mGluRs), which are glutamateactivated $G$ protein-coupled receptors, and ionotropic glutamate receptors (iGluRs), which are tetrameric, glutamate-activated ion channels (Niswender and Conn, 2010; Traynelis et al., 2010; Reiner and Levitz, 2018). A rich repertoire of pharmacological compounds has been developed for both receptor families, which are regarded to be important pharmacological targets.

iGluRs are fundamental to neurotransmission, neuromodulation and plasticity at excitatory synapses. Based on the action of selective agonists iGluRs were subclassified into $\alpha$-amino-3-hydroxy-5-methyl-4-isoxazolepropionic acid (AMPA), kainate and $N$-methyl-D-aspartate (NMDA) receptors. This classification was later confirmed by sequence homology, which also revealed the existence of a fourth class, the $\delta$ receptor family. The first selective antagonists for blocking non-NMDA receptor responses were two quinoxalinedione derivatives (Figure 1), 6,7-dinitroquinoxaline-2,3-dione (DNQX) and 6-cyano-7-nitroquinoxaline-2,3-dione (CNQX) (Honoré et al., 1988), which were reported just prior to cloning of the first iGluRs (Hollmann et al., 1989). NMDA receptor antagonists had been reported earlier (Biscoe et al., 1977). DNQX, CNQX and $\mathrm{NBQX}$, a related quinoxalinedione with somewhat higher selectivity for AMPA than kainate receptors (Sheardown et al., 1990), are still widely used to block AMPA and kainate receptor responses in neurophysiological studies.

Quinoxalinediones act as competitive, i.e. orthosteric, antagonists that bind to the glutamate binding site of AMPA and kainate receptors (for an affinity comparison see Traynelis et al., 2010), and to the glycine binding site of GluN1 and GluN3 NMDA receptor subunits (Yao and Mayer, 2006). Their binding sites (Figure 1B) are located in the extracellular parts of the receptor within the bilobed ligand binding domains (LBDs) (Uchino et al., 1992; SternBach et al., 1994; Armstrong et al., 1998). Glutamate binding leads to closure of these clamshell-like LBDs, which appears to be a requirement for efficient activation. Agonists with lower efficacy appear to induce only 
A<smiles>CC(=O)O[N+](=O)[O-]</smiles><smiles></smiles><smiles>N#Cc1cc2[nH]c(=O)c(=O)[nH]c2cc1[N+](=O)[O-]</smiles>
YM90K
B

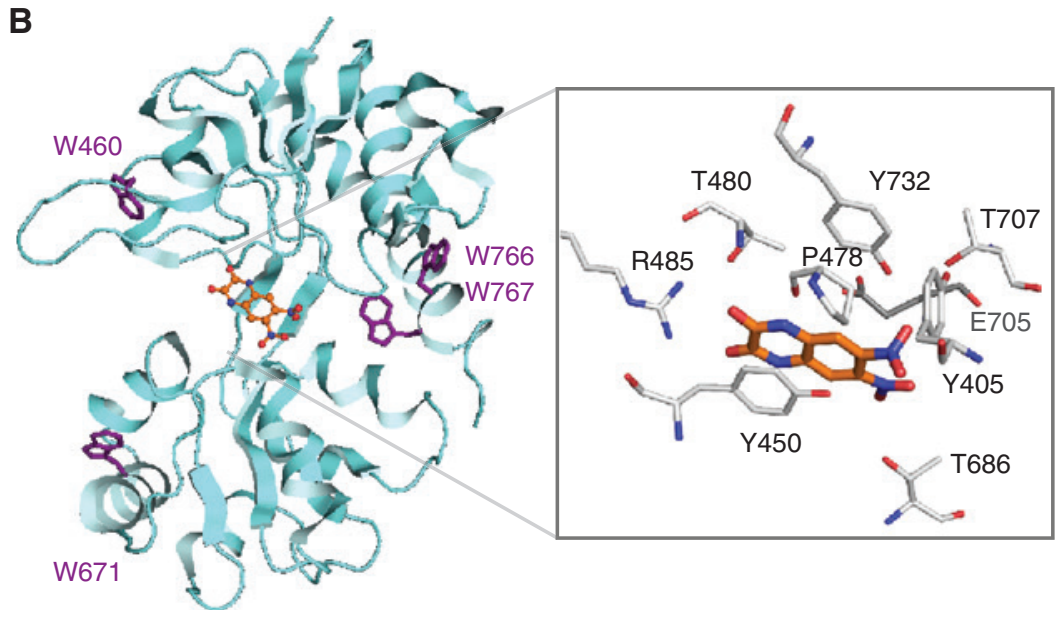

Figure 1: Binding of quinoxalinedione antagonists at the GluA2 ligand binding domain.

(A) Chemical structure of selected quinoxalinedione antagonists. (B) Structure of the GluA2 LBD (S1S2) with bound DNQX (orange). (Left) Cartoon representation showing the LBD and its four Trp residues. (Right) Detailed view of the binding pocket showing selected amino acid side chains. Based on PDB 1FTL (Armstrong and Gouaux, 2000).

partial closure (Armstrong and Gouaux, 2000), whereas competitive antagonists still engage most residues important for agonist binding (Pøhlsgaard et al., 2011), but do apparently not favor (or allow) the transitions necessary for channel opening.

Structures of quinoxalinedione-bound AMPA and kainate receptor LBDs show that these ligands interact with various residues that are also critical for glutamate binding (Figure 1B). The carbonyl groups of their dilactam structure mimic the $\alpha$-carboxylic acid of glutamate by interacting with the guanidinium group of Arg485 in the GluA2 LBD, an arginine residue that is conserved in all iGluRs. In addition, one of their lactam groups seems to engage with the backbone carbonyl of Pro478 and the aromatic system forms a $\pi-\pi$ interaction with Tyr450 (Armstrong and Gouaux, 2000; Menuz et al., 2007). This information obtained from crystal structures of isolated LBDs was confirmed by more recent full-length structures, e.g. of a quinoxalinedione-bound GluA2 tetramer (Sobolevsky et al., 2009), which suggests that isolated LBDs can serve as useful models to address ligand binding.

The role of charged side chains for glutamate binding and gating has been studied in great detail (e.g. Uchino et al., 1992; Swanson et al. 1997; Mah et al., 2005; Weston et al. 2006). Electrostatic interactions might be also important for fast binding by guiding the ligand to the binding site (Yu et al., 2018). Besides, iGluRs are very susceptible to changes in $\mathrm{pH}$, with most subtypes becoming inhibited at lower pH values (e.g. Mott et al., 2003; Traynelis et al., 2010). The inhibitory effects of $\mathrm{pH}$, which differ strongly between receptor subtypes and isoforms, however, are not caused by changes in glutamate ionization or binding affinity, as also shown for the ligands AMPA, kainate and NMDA (Tang et al., 1990; Vyklický et al., 1990; Traynelis and Cull-Candy, 1991). In contrast, the binding affinity may be affected, if ligand protonation or deprotonation occurs close to physiological $\mathrm{pH}$ values, as demonstrated for willardiines, a class of uracil-based agonists (Martinez et al. 2014). Similarly, a recent computational study concluded that deprotonation of quinoxalinedione antagonists may offer a large energetic contribution to binding (De Freitas et al., 2017), while other studies treated quinoxalinediones as neutral entities (Heinzelmann et al, 2014).

Inhibition of glutamatergic signaling has been considered a promising strategy for therapeutic intervention, including epilepsy treatment (Rogawski, 2013), managing excitotoxicity after stroke and injuries (Lai et al., 2014), pain and migraine treatment, as well as controlling mood disorders or addictive behavior. The quinoxalinedione group served as scaffold (Poulie and Bunch, 2013) for the development of several hundred derivatives, with the main goal of achieving improved pharmacological properties. Clinical trials with broadspecificity antagonists, e.g. with the quinoxalinediones ZK 200775 (Turski et al., 1998; Elting et al., 2002), AMP397 and YM872 (Takahashi et al., 2002), a derivative of YM90K, revealed severe side effects, which motivates the development of quinoxalinedione antagonists with increased subtype selectivity. This led to ACEA-1021 and related compounds (Keana et al., 1995) with partial subtype specificity for the GluN1 subunit of NMDA receptors, and very recently also to quinoxalinediones with high selectivity for kainate receptor subtypes (Larsen and Bunch, 2011; Demmer et al., 2017). 
Here, we set out to assess whether fluorescence quenching by quinoxalinediones, such as DNQX and $\mathrm{CNQX}$ can be used to perform ligand binding assays at purified iGluR LBDs in vitro, which would be a useful complement to radioligand binding assays. Using the GluA2 AMPA receptor LBD, we show that fluorescence quenching allows to directly follow DNQX and CNQX binding, and that this assay can be further used in competition experiments to measure the binding affinity of non-fluorescent ligands. Moreover, our experiments reveal that DNQX and CNQX binding to the GluA2 LBD is strongly $\mathrm{pH}$ dependent, which we attribute to the deprotonation of the quinoxaline-2,3(1H,4H)-dione scaffold occurring below or at physiological $\mathrm{pH}$ values. This deprotonation appears to be a key, but previously neglected requirement for high affinity binding at iGluRs.

\section{Results}

\section{DNQX- and CNQX-mediated fluorescence quenching can be used to monitor ligand binding at the GluA2 LBD}

To perform in vitro ligand binding assays we expressed the isolated GluA2 LBD (His-GluA2.S1S2; Armstrong and Gouaux, 2000) in Escherichia coli and purified it using Ni-NTA affinity chromatography. The GluA2 LBD harbors 4 tryptophan (Trp) and 13 tyrosine (Tyr) residues (Figure 1B), which we utilized as intrinsic fluorophores. Excitation of the GluA2 LBD with $280 \mathrm{~nm}$ or $295 \mathrm{~nm}$ light yields fluorescence with an emission maximum at $\sim 335 \mathrm{~nm}$ [Figure $2 \mathrm{~A}$ and Figure S1, see Supplementary Information (SI)], which is consistent with the Trp residues being in a partially hydrophobic environment. Intriguingly, the fluorescence emission overlaps with the absorbance of DNQX, a prototypic quinoxalinedione-type iGluR antagonist that binds to the glutamate binding pocket (Figure 1). A previous study has shown that DNQX binding strongly decreases the fluorescence intensity of the GluA2 LBD, likely due to efficient energy transfer to DNQX (Petrik et al., 2010), which is non-fluorescent. Indeed, addition of DNQX to an extensively dialyzed, ligand free GluA2 LBD decreased the fluorescence emission to $<20 \%$ (Figure 2A). The spectral shape of the fluorescence emission was not changed by DNQX binding (Supplementary Figure S1).

In contrast to the strong fluorescence quenching caused by DNQX binding, the structural rearrangements of the LBD that are associated with ligand binding and clamshell closure were reported to cause only a minor decrease of the fluorescence intensity (Abele et al., 2000). When we added a high concentration of glutamate to the DNQX-bound LBD we observed partial recovery of the fluorescence (Figure 2A). This confirms that the strong fluorescence decrease was indeed due to quenching by bound DNQX, which can be reversed by the addition of glutamate that competes for the same binding site.
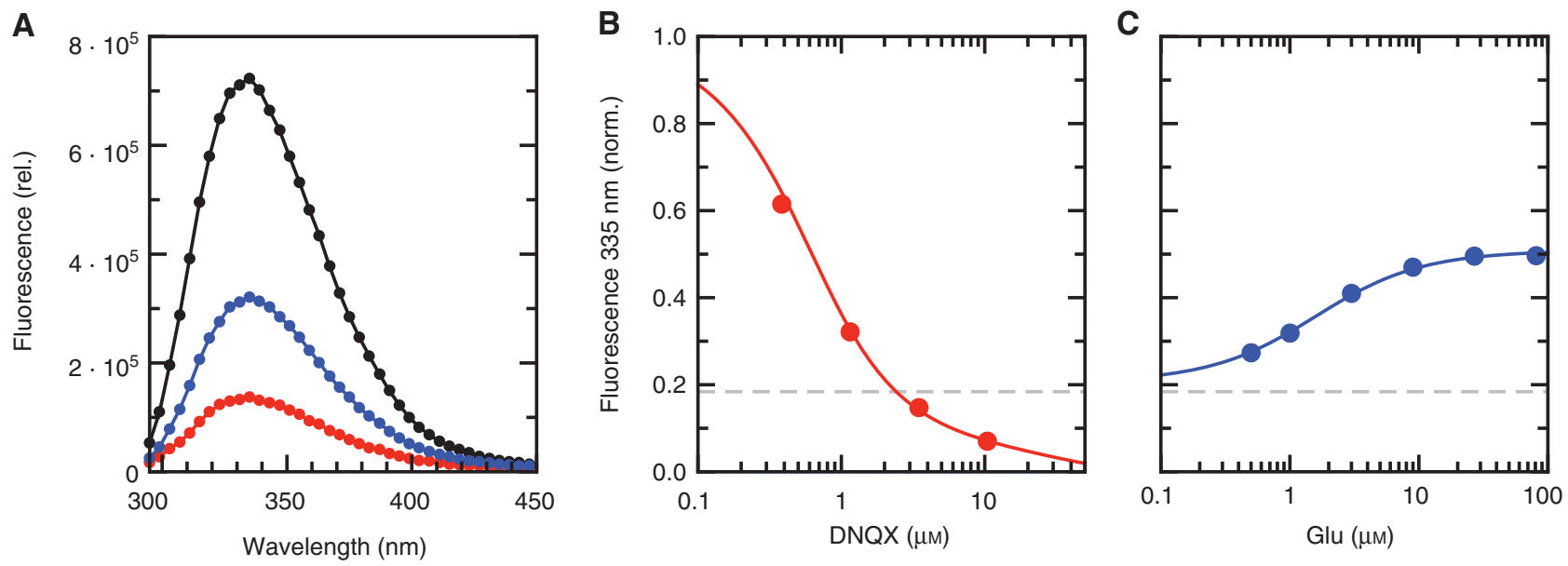

Figure 2: Fluorescence decrease of the GluA2 LBD upon DNQX binding and partial fluorescence recovery upon glutamate addition. (A) Fluorescence emission spectra of the GluA2 LBD in the absence of ligand (black), after addition of 2.41 $\mu \mathrm{M}$ DNQX (red), and after subsequent addition of $81 \mu \mathrm{m}$ glutamate (blue). (B) Decrease of the fluorescence emission at $335 \mathrm{~nm}$ upon DNQX addition. The fluorescence intensity was normalized to the fluorescence intensity of the apo-LBD. The solid line shows the fit of a 1:1 binding model (Eq. 2a-c), which yielded $K_{d}^{\text {DNQX }}=(0.322 \pm 0.048) \mu \mathrm{M}$ and $A^{\text {DNQX.LBD }}=(7 \pm 1) \%$. (C) Partial recovery of the fluorescence emission upon addition of glutamate in the presence of $2.41 \mu \mathrm{M}$ DNQX (dashed line). The solid lines show the fit of a direct competition model (Eq. S2a-h), which yielded $K_{\mathrm{d}}^{\text {Glu }}=(0.159 \pm 0.024) \mu \mathrm{M}$ and $\mathrm{A}^{\text {Glu.LBD }}=(54 \pm 1) \%$. Measurements were performed with $0.5 \mu \mathrm{M}$ GluA2 LBD in $50 \mathrm{~mm} \mathrm{NaCl,} 20 \mathrm{~mm}$ HEPES, pH 6.0 and excitation at $280 \mathrm{~nm}$ ( $2 \mathrm{~nm}$ slit width). The emission was collected with $4 \mathrm{~nm}$ slit width in $4 \mathrm{~nm}$ increments. 

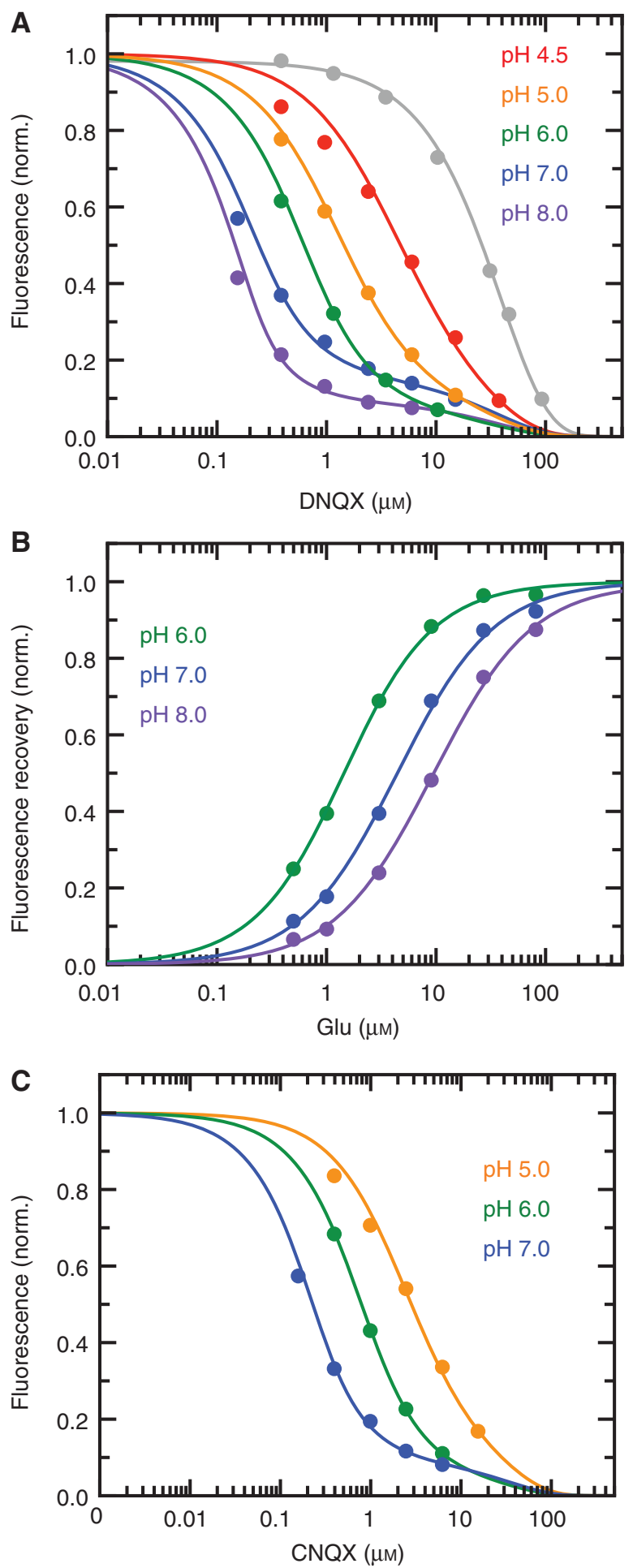

Our goal was to utilize the strong fluorescence quenching mediated by DNQX binding to perform in vitro ligand binding assays. To have precise knowledge of the used ligand concentrations we determined the molar extinction coefficients of DNQX and CNQX using a nuclear magnetic resonance (NMR)-based approach and absorbance measurements (see SI).
Figure 3: DNQX binding to the GluA2 LBD is pH-dependent, but not glutamate binding.

(A) Titration of the apo-GluA2 LBD with DNQX at pH 8.0, $\mathrm{pH}$ 7.0, $\mathrm{pH} 6.0, \mathrm{pH} 5.0$ and $\mathrm{pH} 4.5$, from left to right (colors as indicated). The fluorescence emission at $335 \mathrm{~nm}$ was normalized to the emission intensity of the apo-LBD. The binding affinity is highest at $\mathrm{pH} 8$ and decreases at lower pH. The lines show fits of Eq. $2 \mathrm{a}-\mathrm{c}$ with the parameters given in Table S2. The LBD concentration was $0.2 \mu \mathrm{m}$ at $\mathrm{pH} 8.0$ and $\mathrm{pH} 7.0$, and $0.5 \mu \mathrm{m}$ at all other $\mathrm{pH}$ values. The contribution from inner filter effects is shown in grey (see Figure 54 ).

(B) Competition between glutamate and $\mathrm{DNQX}$ binding at $\mathrm{pH}$ 6.0, $\mathrm{pH} 7.0$ and $\mathrm{pH}$ 8.0, from left to right. Glutamate was added to $0.5 \mu \mathrm{M}$ GluA2 LBD in the presence of $2.41 \mu \mathrm{M}$ DNQX. Fitting of Eq. S2h (solid lines) was used to analyze and normalize the data with the parameters given in Table S2. Data at $\mathrm{pH} 6.0$ were taken from Figure 2. (C) Titration of the apo-GluA2 LBD with CNQX at $\mathrm{pH} 7.0, \mathrm{pH} 6.0$ and pH 5.0 from left to right (colors as indicated). The lines show fits of Eq. $2 \mathrm{a}-\mathrm{c}$ (parameters given in Table S2). The LBD concentration was $0.2 \mu \mathrm{M}$ at pH 7.0, and $0.5 \mu \mathrm{M}$ at pH 6.0 and pH 5.0.

We performed titrations by adding increasing amounts of DNQX to $0.5 \mu \mathrm{M}$ ligand-free GluA2 LBD and analyzed the DNQX-mediated fluorescence decrease with a general binding model assuming 1:1 stoichiometry (Figure 2B). Since DNQX shows a strong absorption in the spectral region of Trp excitation and fluorescence emission [280 $\mathrm{nm}$ and $335 \mathrm{~nm}$, respectively (Table S1)], free DNQX is expected to cause an apparent signal decrease, when used at high concentrations (inner filter effects). The inner filter effects became detectable at DNQX concentrations $\geq 3 \mu \mathrm{M}$ (Figure S4) but were taken into account for non-linear least square fitting, see Eq. 2a-c (see Material and methods). We obtained a dissociation constant $K_{\mathrm{d}}^{\mathrm{DNQX}}=(0.322 \pm 0.048) \mu \mathrm{M}(\mathrm{pH} 6.0)$ and a reduction of the initial apo-LBD fluorescence due to DNQX binding to $\mathrm{A}^{\mathrm{DNQX} \cdot \mathrm{LBD}}=(7 \pm 1) \%$ (Figure $\left.2 \mathrm{~B}\right)$.

Addition of increasing amounts of glutamate to the DNQX-bound GluA2-LBD caused DNQX displacement and a partial recovery of the fluorescence (Figure 2C). We analyzed this competition between glutamate and DNQX binding with a three-state model (Eq. 3 and SI). Using the previously determined $K_{\mathrm{d}}^{\mathrm{DNOx}}$, we obtained $K_{\mathrm{d}}^{\mathrm{Glu}}=(0.159 \pm 0.024) \mu \mathrm{M}(\mathrm{pH}$ 6.0). For the fluorescence intensity of the glutamate-bound GluA2 LBD compared to the apo-LBD we found $\mathrm{A}^{\mathrm{Glu} \cdot \mathrm{LBD}}=(54 \pm 1) \%$.

\section{DNQX and CNQX binding is pH dependent, but not glutamate binding}

When we performed ligand binding assays at different $\mathrm{pH}$ values, we observed that DNQX binding at the GluA2 LBD was strongly $\mathrm{pH}$ dependent (Figure 3A). Qualitative 
inspection shows that at higher $\mathrm{pH}$ less $\mathrm{DNQX}$ is required to achieve half-maximal fluorescence quenching. At $\mathrm{pH} \geq 7$ the affinity became so high that we lowered the LBD concentration from $0.5 \mu \mathrm{M}$ to $0.2 \mu \mathrm{M}$ to avoid purely stoichiometric titrations. At high binding affinities DNQX-mediated fluorescence quenching remains well separated from the inner filter effects, which results in a distinct plateau in the titration curves at around $15 \%$ fluorescence intensity.

By analyzing the data shown in Figure $3 \mathrm{~A}$ we determined the apparent dissociation constants, $K_{\mathrm{d}}^{\mathrm{DNQX}}$, which ranged over two orders of magnitude, from $K_{\mathrm{d}}^{\mathrm{DNQX}}=(3.60 \pm 0.54) \mu \mathrm{M}$ at $\mathrm{pH} 4.5$ to $K_{\mathrm{d}}^{\mathrm{DNQX}}=(0.031 \pm 0.005) \mu \mathrm{M}$ at $\mathrm{pH}$ 8.0. The fluorescence decrease due to DNQX was not systematically affected by $\mathrm{pH}$ (Table S2), which suggests that the mode of DNQX binding and the efficacy of quenching remained unchanged. Also, the fluorescence properties of the apo-GluA2 LBD were not affected by pH (Figure S3). For CNQX, the other quinoxalinedione antagonist we tested, we observed a similar amount of fluorescence quenching (Figure S2), a similar overall affinity, and a similar decrease in binding affinity with decreasing $\mathrm{pH}$ (Figure 3C and Table S2).
We next asked, whether $\mathrm{pH}$ also affects the affinity of glutamate binding. We therefore chose $\mathrm{pH} 7.0$ and $\mathrm{pH} 8.0$ to perform additional glutamate competition experiments in the presence of DNQX (Figure 3B). The analysis with the corresponding competition model revealed that the observed shift in the competition curves is explained solely by the 10 -fold increase in DNQX affinity between $\mathrm{pH}$ 6.0 and $\mathrm{pH}$ 8.0, whereas the glutamate affinity remains unchanged in this $\mathrm{pH}$ range (Table S2). This finding indicates that the observed $\mathrm{pH}$ dependence in DNQX and CNQX binding is likely due to $\mathrm{pH}$-dependent processes in the quinoxalinedione ligand, rather than due to protonation changes of the GluA2 LBD or buffer components.

\section{Quinoxalinedione antagonists deprotonate at physiological $\mathrm{pH}$ values}

DNQX and CNQX are representative quinoxaline-2,3 $(1 \mathrm{H}, 4 \mathrm{H})$-diones, which can undergo tautomerism at the two lactam-lactim functionalities (Figure 4A). To assess

A

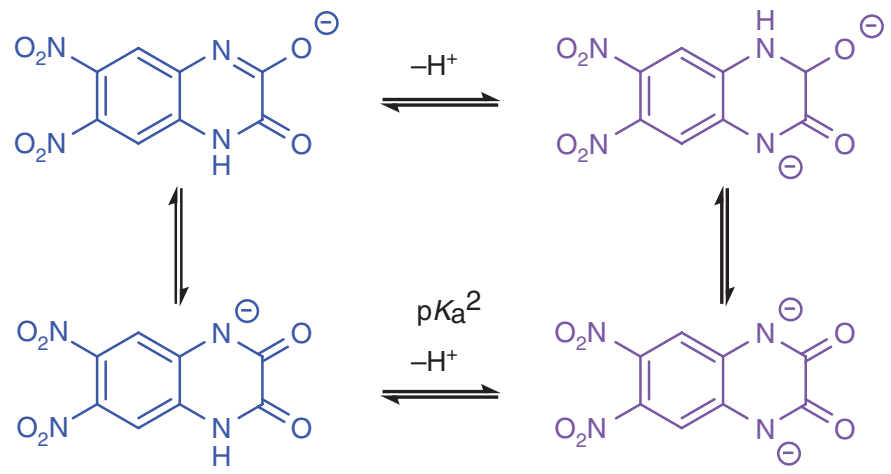
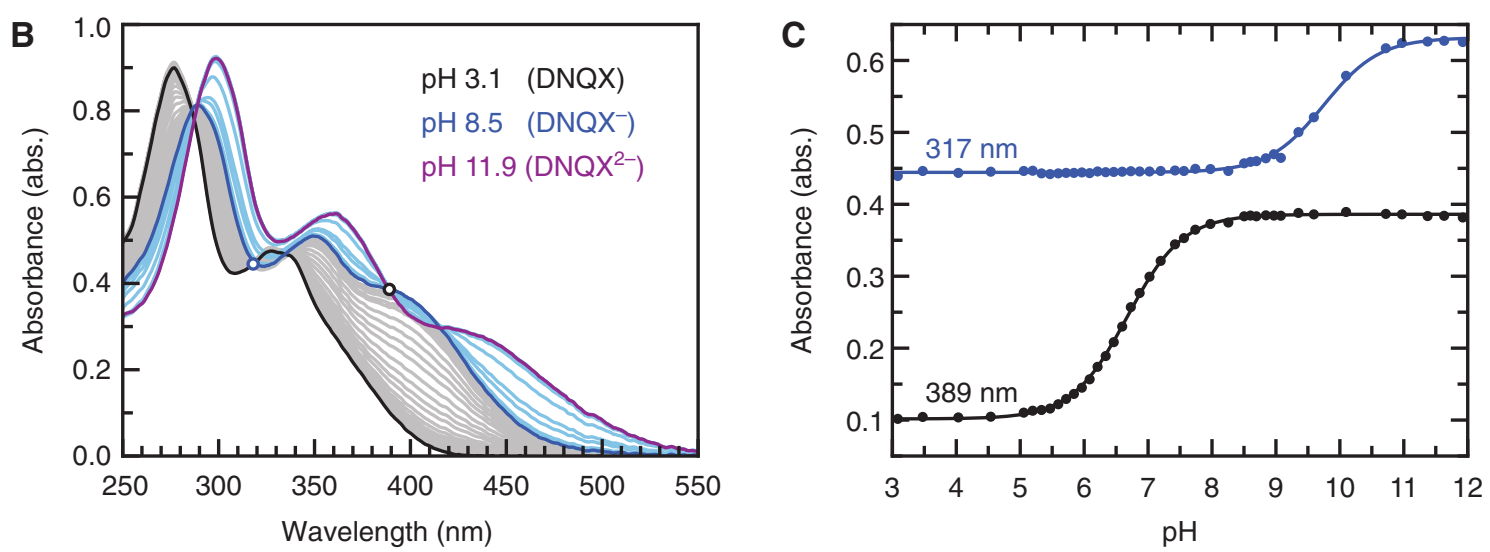

Figure 4: Absorbance measurements at different $\mathrm{pH}$ values reveal deprotonation of DNQX.

(A) Scheme showing the diprotic nature of DNQX. The quinoxaline-2,3(1H,4H)-dione can undergo a lactam-lactim (amide-iminol) tautomerization. (B) DNQX absorbance spectra in the range of $\mathrm{pH} 3-12$, measured with $38 \mu \mathrm{M}$ DNQX. The spectra and the two separate sets of isosbestic points demonstrate the existence of three differently absorbing species, which we attribute to DNQX (black), DNQX- (blue) and DNQX2- (purple). (C) Absorbance at two different isosbestic points, $317 \mathrm{~nm}$ and $389 \mathrm{~nm}$ as a function of pH. A global fit of Eq. 4 (lines) gives $\mathrm{p} K_{\mathrm{a}}^{1}=6.68 \pm 0.01$ and $\mathrm{p} K_{\mathrm{a}}^{2}=9.77 \pm 0.01$, respectively (for details see Figure $\mathrm{S} 5$ ). 
pH-dependent changes of DNQX and other quinoxalinediones, we measured absorbance spectra between $\mathrm{pH} 3-12$ (Figures 4B,C and S5-8). With increasing $\mathrm{pH}$, the DNQX absorption extends to longer wavelengths, and while the spectra lack a common isosbestic point, they are fully consistent with two $\mathrm{pH}$-dependent transitions between three spectroscopically different species.

We analyzed the absorbance changes at a larger set of wavelengths (Eq. 4, Figure S5), which confirmed the diprotic behavior of DNQX. The $\mathrm{p} K$ a values we obtain, $\mathrm{p} K_{\mathrm{a}}^{1}=6.68 \pm 0.01$ and $\mathrm{p} K_{\mathrm{a}}^{2}=9.77 \pm 0.01$, are similar to the data reported by De Freitas et al. (2017), who attributed the transitions to the deprotonation of neutral DNQX to the monoanion $\left(\mathrm{p} K_{\mathrm{a}}^{1}\right)$, and of $\mathrm{DNQX}^{-}$to the dianion $\left(\mathrm{p} K_{\mathrm{a}}^{2}\right)$, respectively (Figure $4 \mathrm{~A}$ ). For CNQX we observed similar spectral changes and $\mathrm{p} K_{\mathrm{a}}$ values, as the deprotonation to the monoanion occurs with $\mathrm{p} K_{\mathrm{a}}^{1}=6.78 \pm 0.01$ (Figure S6). In contrast, $\mathrm{NBQX}$ and YM90K (Figure 1A), showed more complex behavior due to additional protonation/deprotonation reactions at their substituents (Figure S7-8). The literature data for YM90K, however, suggests that the first lactim deprotonation occurs with a similar $\mathrm{p} K_{\mathrm{a}}$ value (Ohmori et al., 1994). Overall, this data shows that it is a common property of quinoxalinedione-type iGluR antagonists to be, at least in part, negatively charged at physiological $\mathrm{pH}$ values.

\section{Quinoxalinedione deprotonation is a key determinant for binding at the GluA2 LBD}

Apparently, the monoanionic form of quinoxaline-2,3 $(1 H, 4 H)$-diones binds with higher affinity than their protonated, neutral form. To quantify the contribution of quinoxalinedione deprotonation to binding, we treated protonation/deprotonation and binding/unbinding at the LBD as thermodynamically coupled equilibria (Figure $5 \mathrm{~A}$ and the supplementary material). The $\mathrm{pH}$ dependence of the observed dissociation constant $K_{\mathrm{d}}(\mathrm{pH})$ can then be written as a function of the $\mathrm{p} K_{\mathrm{a}}$ of the free (unbound) ligand, $\mathrm{p} K_{\mathrm{a}}^{\text {free }}$, the dissociation constant of the neutral ligand, $K_{\mathrm{d}}^{0}$, and the dissociation constant of the negatively charged ligand, $K_{\mathrm{d}}^{-}$:

$$
K_{\mathrm{d}}(\mathrm{pH})=\frac{K_{\mathrm{d}}^{0} \cdot K_{\mathrm{d}}^{-} \cdot\left(10^{\mathrm{pH}}+10^{\mathrm{p} K_{\mathrm{a}}^{\text {fee }}}\right)}{K_{\mathrm{d}}^{0} \cdot 10^{\mathrm{pH}}+K_{\mathrm{d}}^{-} \cdot 10^{\mathrm{p} K_{\mathrm{a}}^{\text {fee }}}}
$$

We plotted the apparent $K_{\mathrm{d}}$ values of DNQX and CNQX as a function of $\mathrm{pH}$ and analyzed them using Eq. 1 (Figure 5B). Using non-linear least square fitting we found that the coupled binding/deprotonation model (Figure 5A) describes the data reasonably well. Relying on our previously determined $\mathrm{p} K_{\mathrm{a}}^{1}$ for the first deprotonation of free
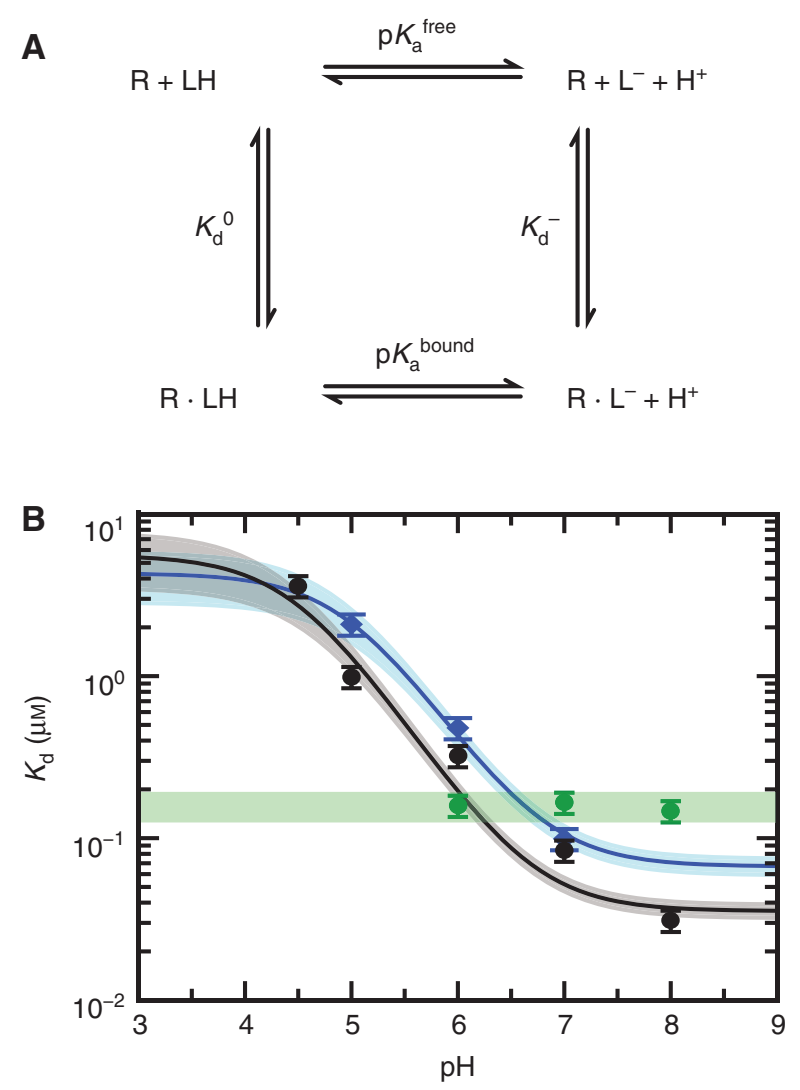

Figure 5: Coupling of ligand binding and quinoxalinedione deprotonation.

(A) Scheme of the linked deprotonation/protonation and binding/ unbinding equilibrium. $R$ denotes the receptor (the GluA2 LBD) and $\mathrm{LH}$ a protonated ligand (e.g. DNQX). $\mathrm{p} K_{\mathrm{a}}^{\text {free }}$ and $\mathrm{p} K_{\mathrm{a}}^{\text {bound }}$ describe the tendency of the ligand to deprotonate in the free and receptorbound state, respectively, whereas the dissociation constants $K_{\mathrm{d}}^{0}$ and $K_{\mathrm{d}}^{-}$describe the binding affinities of the protonated and deprotonated ligand, respectively. Due to microscopic reversibility one of the four equilibrium constants is determined by the other three, e.g. $\mathrm{p} K_{\mathrm{a}}^{\text {bound }}=\mathrm{p} K_{\mathrm{a}}^{\text {free }}-\log \left(K_{\mathrm{d}}^{0} / K_{\mathrm{d}}^{-}\right)$. (B) The apparent dissociation constants of DNQX (black points) and CNQX (blue points) show a strong $\mathrm{pH}$ dependence, whereas glutamate dissociation (green points) shows virtually no $\mathrm{pH}$ dependence. The analysis with the four-state model shown in panel (A) (Eq. 1) yields for DNQX $\left(\mathrm{p} K_{\mathrm{a}}^{\text {free }}=6.68\right)$ estimates of $K_{\mathrm{d}}^{0}=(5.59 \pm 2.09) \mu \mathrm{M}$ and $K_{\mathrm{d}}^{-}=(0.035 \pm 0.003) \mu \mathrm{M}$. For $\mathrm{CNQX}\left(\mathrm{p} K_{\mathrm{a}}^{\text {free }}=6.78\right)$ it yields $K_{\mathrm{d}}^{0}=(4.32 \pm 1.47) \mu \mathrm{m}$ and $K_{\mathrm{d}}^{-}=(0.067 \pm 0.008) \mu \mathrm{m}$. The colored regions give the confidence regions determined in the fitting procedure.

DNQX $\left(\mathrm{p} K_{\mathrm{a}}^{\text {free }}=6.68\right)$, we obtain $K_{\mathrm{d}}^{0}=(5.59 \pm 2.09) \mu \mathrm{M}$ and $K_{\mathrm{d}}^{-}=(0.035 \pm 0.003) \mu \mathrm{M}$ for the dissociation of neutral $\mathrm{DNQX}^{0}$ and negatively charged $\mathrm{DNQX}^{-}$, respectively (Figure 5B).

This difference between the dissociation constants $K_{\mathrm{d}}^{0}$ and $K_{\mathrm{d}}^{-}$suggests that the monoanionic form of DNQX has a 160 -fold higher binding affinity than its uncharged counterpart, which corresponds to a difference in binding 
free energy of $\sim-12 \mathrm{~kJ} / \mathrm{mol}$. Our data also suggests that at $\mathrm{pH} 7.0$ the binding affinity of DNQX is still reduced by the presence of the neutral form with $K_{\mathrm{d}}(\mathrm{pH} 7$ ) being $\sim 2.5$-fold higher than $K_{\mathrm{d}}^{-}$. However, it should be noted that these values, in particular $K_{\mathrm{d}}^{0}$, are associated with relatively large errors since our measurements do not fully capture this large drop in affinity. Another limitation is that we only considered the first quinoxalinedione deprotonation, although the second deprotonation $\left(\mathrm{p} K_{\mathrm{a}}^{2}=9.77\right)$, which could further increase or decrease the affinity, may start playing a role at $\mathrm{pH} 8$. For CNQX $\left(\mathrm{p} K_{\mathrm{a}}^{\text {free }}=6.78\right)$ our analysis yielded very similar data, $K_{\mathrm{d}}^{0}=(4.32 \pm 1.47) \mu \mathrm{M}$ and $K_{\mathrm{d}}^{-}=(0.067 \pm 0.008) \mu \mathrm{M}$ (Figure $\left.5 \mathrm{~B}\right)$.

\section{Discussion}

\section{Quinoxalinedione-based fluorescence quenching assays}

Given the physiological importance of iGluRs and the continued efforts to synthesize new and subunit-selective ligands, the development of versatile yet simple and robust binding assays is desirable. In this study we evaluated whether DNQX and CNQX, which quench the intrinsic fluorescence of the GluA2 LBD, can be used to perform in vitro ligand binding assays.

An earlier study had shown that binding of DNQX, which is a prototypic quinoxalinedione-type, competitive antagonist causes quenching of the intrinsic Trp/Tyr fluorescence of the GluA2 LBD (Petrik et al., 2010). This fluorescence quenching was attributed to efficient Förster resonance energy transfer (FRET) from the Trp/Tyr residues to DNQX, which strongly absorbs in the wavelength range of Trp/Tyr fluorescence emission (Figure 4) and can thus serve as non-fluorescent acceptor. Efficient FRET is consistent with the four Trp residues being in close proximity of the binding pocket $(<20 \AA)$ and an estimated Förster radius of $33 \AA$, which results in a shortening of the fluorescence lifetimes of all Trp residues upon DNQX binding (Petrik et al., 2010). Related quinoxalinedione antagonists, which have similar spectroscopic properties (Figure S5-8) should also act as fluorescence quenchers, as we could demonstrate for CNQX binding (Figure S2). However, some part of the quenching effect appears to be mediated by other mechanisms, as binding of glutamate also causes a moderate reduction in fluorescence intensity (Abele et al., 2000; Petrik et al., 2010). The spectral changes upon quinoxalinedione deprotonation (Figure 4) would result in only a negligible change of the Förster radius.
Our goal was to utilize this strong fluorescence quenching effect for quantitative binding studies. In agreement with our expectations, DNQX addition to the apo-LBD caused a strong decrease in fluorescence intensity, which could be partially reversed by adding high, competing concentrations of glutamate (Figure 2). DNQX binding decreased the fluorescence intensity to $<15 \%$ compared to the apo-LBD, independent of $\mathrm{pH}$ (Table S2). Glutamate binding decreased the fluorescence intensity to $\sim 70 \%$ (pH 8.0), which is a somewhat stronger reduction than reported previously (Abele et al., 2000; Petrik et al., 2010).

We performed a set of titration experiments at different $\mathrm{pH}$ values (Figure 3). For DNQX our data revealed an apparent dissociation constant of $K_{\mathrm{d}}^{\mathrm{DNQX}}=(0.084 \pm 0.013) \mu \mathrm{M}$ at $\mathrm{pH} 7.0$ and $20^{\circ} \mathrm{C}$. For CNQX we found a slightly lower affinity with $K_{\mathrm{d}}^{\mathrm{CNQX}}=(0.099 \pm 0.015) \mu \mathrm{M}$ at $\mathrm{pH} 7.0$ and $20^{\circ} \mathrm{C}$. These values are similar to affinities reported from radioligand binding assays performed at the GluA2 LBD (Armstrong and Gouaux, 2000; Ahmed et al., 2009) and full-length receptors (Keinänen et al., 1990; Andersen et al., 1996).

The dynamic range of our quenching assay can be assessed by comparing the data shown in Figure 3A. High affinity binding with $K_{\mathrm{d}}<<[\mathrm{LBD}]$ results in stoichiometric binding curves, which report on binding stoichiometry rather than affinity. Although we begin to approach this limit at $\mathrm{pH} 8$, we were still able to determine the dissociation constant $\left[K_{\mathrm{d}}^{\mathrm{DNQX}}=(0.031 \pm 0.005) \mu \mathrm{M}\right]$. The high quality of the corresponding fit confirms the expected 1:1 ligand/ LBD stoichiometry and shows that the LBD and DNQX concentrations were determined correctly. In contrast, low affinity binding requires high quinoxalinedione concentrations, at which the inner filter effects will reduce the fluorescence intensity in addition to fluorescence quenching mediated by binding. Taking the inner filter effects into account (Eq. 2c), our measurements remain reliable down to $\mathrm{pH} 4.5\left[K_{\mathrm{d}}^{\mathrm{DNQX}}=(3.60 \pm 0.54) \mu \mathrm{M}\right]$. Even lower ligand affinities could be measured after optimizing the sample geometry to minimize the inner filter effects, or by relying on fluorescence lifetime measurements as read-out.

The main utility of DNQX and CNQX quenching will be in competitive binding assays. Addition of glutamate to a DNQX-bound GluA2 LBD restored the fluorescence to the value that is expected for the glutamate-bound LBD, $\mathrm{A}^{\text {Glu.LBD }}$. Analysis of our competition experiments yielded $K_{\mathrm{d}}^{\mathrm{Glu}}=0.166 \pm 0.025 \mu \mathrm{M}\left(\mathrm{pH} 7.0\right.$ and $\left.20^{\circ} \mathrm{C}\right)$ for glutamate dissociation from the GluA2 LBD, which is comparable to data obtained by other means (Keinänen et al., 1990; Chen and Gouaux, 1997; Abele et al., 2000; Deming et al., 2003). Competition assays also overcome the problem of the limited stability of the ligand-free LBDs that is observed under some conditions. 
Our fluorescence quenching assay should thus be a useful alternative to commonly used radioligand binding assays, as it combines reasonable sensitivity with simple handling. The assay is not limited to competition with glutamate, but may be used for any other ligands, which are optically inactive, i.e. that do not strongly absorb, show fluorescence or quench fluorescence in this wavelength region. The dynamic range of the assay may be extended by changing the $\mathrm{pH}$ at which the quinoxalinedione competition is performed, if the ligand under investigation does not titrate in this range. Alternatively, high affinity quinoxalinedione antagonists may be used.

\section{The deprotonation of quinoxalinedione antagonists occurs close to physiological pH}

An important finding from our study is that quinoxalinedione binding at the GluA2 LBD is $\mathrm{pH}$ dependent, which prompted us to evaluate their deprotonation behavior using absorption measurements. Indeed, for the four common quinoxalinedione antagonists we tested, we could confirm that deprotonation occurs below or at physiological $\mathrm{pH}$ values.

The acidic nature of quinoxalinediones can be rationalized by considering the tautomerization of their lactamlactim functionalities (amide-iminol tautomerization) (Figure 4A). The deprotonation of the amide/iminol is favored, as the remaining negative charge can be delocalized to the carbonyl group. The unsubstituted parent compound, quinoxaline-2,3(1H,4H)-dione, is reported to deprotonate with $\mathrm{p} K_{\mathrm{a}}^{1}=9.7$ (Krishnamurthy et al., 1987), which is an untypical low $\mathrm{p} K_{\mathrm{a}}$ for amides. The electron withdrawing effect of the pseudo-para-nitro or nitrile groups in DNQX and CNQX shifts this $\mathrm{p} K_{\mathrm{a}}$ to $<7$. The substitutions in NBQX and YM90K (Figure 1A) are similarly effective in favoring the deprotonation (Figure S7/8; Ohmori et al., 1994; Cordi et al., 1995).

The deprotonation of quinoxalinediones has received little attention so far, given that it occurs close to physiological pH. A notable exception is the structure-function study by Cordi et al. (1995). Their experimental estimation of $\mathrm{p} K_{\mathrm{a}}$ values of quinoxalinediones with different substitution patterns showed that nitro-substituents in the pseudo-para-position are particularly effective in lowering the $\mathrm{p} K_{\mathrm{a}}$, and, in lowering the concentration needed to inhibit kainate induced receptor currents. The only other study directly addressing the consequences of quinoxalinedione deprotonation appears to be the work by De Freitas et al. (2017), which reports almost identical absorption spectra for DNQX and slightly higher $\mathrm{p} K_{\mathrm{a}}$ values $\left(\mathrm{p} K_{\mathrm{a}}^{1}=6.99, \mathrm{p} K_{\mathrm{a}}^{2}=10.57\right)$.

\section{The high affinity of the quinoxalinedione anion suggests a large electrostatic contribution to iGluR binding}

We found that DNQX and CNQX binding at the GluA2 LBD was strongly $\mathrm{pH}$-dependent, whereas the glutamate affinity was not affected by $\mathrm{pH}$ (Figure 3 ). We concluded that deprotonation of the quinoxalinedione scaffold is important for binding and treated quinoxalinedione deprotonation and binding as thermodynamically coupled equilibrium (Figure 5). This analysis suggests that the anionic form of DNQX has a $\sim 160$-fold higher binding affinity than its uncharged counterpart, corresponding to a difference in binding free energy of $\sim-12 \mathrm{~kJ} / \mathrm{mol}$.

The high affinity of deprotonated quinoxalinediones is readily explained by considering the features of the orthosteric binding site located in the LBD (Figure 1B). A key interaction for ligand binding is provided by Arg485, which interacts with the $\alpha$-carboxylic acid of glutamate and is conserved in all iGluR subtypes (Armstrong et al., 1998). All high-resolution structures of quinoxalinediones bound to GluA2, GluA3 and GluK1 LBDs show the dione group of quinoxalinediones directly juxtaposed to the guanidinium group of this arginine (Armstrong and Gouaux, 2000; Menuz et al., 2007; Cruz et al., 2008; Sobolevsky et al., 2009; Holley et al., 2012; Demmer et al., 2015). The energetic importance of electrostatic interactions with this conserved arginine side chain is also highlighted by the strong loss in glutamate binding affinity, when this residue is replaced by other amino acid side chains (Uchino et al., 1992; Wafford et al., 1995; Abele et al., 2000). Indeed, most orthosteric agonists or antagonists of iGluRs appear to carry a carboxylate to satisfy this interaction (Pøhlsgaard et al., 2011), with the exception of quinoxalinediones, related acidic lactam heterocycles, or heterocycles carrying sulfonamide and phosphonic acid groups (Poulie and Bunch, 2013). The deprotonation of quinoxalinediones thus allows for an equivalent electrostatic interaction. In addition, the negative charge may partially delocalize to the pseudo-parasubstituents, e.g. the nitro groups in DNQX.

De Freitas and colleagues addressed the role of quinoxalinedione deprotonation computationally and reached the same conclusion, namely that the deprotonated DNQX monoanion should significantly contribute to the free energy of binding (De Freitas et al., 2017). The deprotonation of quinoxalinediones also results in overall changes of their electronic structure. Earlier infrared and absorbance 
studies reported spectral shifts for CNQX and DNQX upon receptor binding, which, however, were not directly attributed to protonation changes (Madden et al., 2001; Deming et al., 2003). The red-shift in the absorbance upon quinoxalinedione deprotonation (Figures S5-8) may also explain the large, bathochromic shift that was observed for the action spectrum of a photoswitchable quinoxalinedione antagonist, ShuBQX, upon receptor binding (Barber et al., 2017). Very importantly, due to energetic coupling (Figure 5A) even quinoxalinediones with $\mathrm{p} K_{\mathrm{a}}$ values above physiological $\mathrm{pH}$ may deprotonate upon binding.

Our study was confined to quinoxalinedione binding at the GluA2 LBD. The importance of quinoxalinedione deprotonation may be similarly important for kainate and NMDA receptor binding, which awaits experimental confirmation. Future work should also address, whether quinoxalinedione deprotonation controls the extent of clamshell closure, and, how it affects the potency of glutamate receptor inhibition using functional measurements on full-length receptors. This is of particular interest as channel gating is also influenced by the ligand occupancy at the four binding sites of the receptor tetramer (Rosenmund et al., 1998; Reiner and Isacoff, 2014). Notably, auxiliary transmembrane AMPA receptor regulatory proteins (TARPs) (Menuz et al., 2007), as well as a mutation in the pore region (Taverna et al., 2000; Klein and Howe, 2004), can convert the antagonistic action of DNQX and CNQX into agonism.

\section{Conclusions}

The strong $\mathrm{pH}$ dependence of quinoxalinedione binding has a number of practical consequences. Most obviously, differences in $\mathrm{pH}$ and ionic strength should be taken into account for comparing binding data. For structure-function studies on quinoxalinediones it becomes paramount to determine the $\mathrm{p} K_{\mathrm{a}}$ values of the compounds under investigation, as even slight shifts in their tendency to deprotonate will affect glutamate receptor binding. Moreover, standard experiments in neurophysiology as well as envisioned clinical applications may be affected by quinoxalinedione deprotonation. To avoid unspecific effects, antagonists are typically applied at only moderately higher concentrations than required for efficient inhibition, but even a moderate drop in $\mathrm{pH}$ lowers the efficiency of quinoxalinediones to compete with glutamate: For DNQX and CNQX our data suggests an approximately fivefold affinity decrease between $\mathrm{pH} 7.5$ and $\mathrm{pH}$ 6.0. This could also reduce the potency of these drugs in clinical settings, which may be of particular importance in ischemic stroke conditions, in which antagonists are sought to provide neuroprotection
(Sheardown et al., 1990; Keana et al., 1995; Turski et al., 1998; Takahashi et al., 2002; Lai et al., 2014) but acidosis (Sun et al., 2012) may render them ineffective. Finally, quinoxalinedione deprotonation may also be important for binding to other molecular targets (Xie et al., 2014).

\section{Materials and methods}

\section{Compounds}

DNQX (CAS 2379-57-9), CNQX (CAS 115066-14-3), NBQX (CAS 11887658-7) and YM90K (CAS 154164-30-4) were obtained from Alomone Labs. The concentration of DNQX and CNQX stock solutions was determined spectroscopically using extinction coefficients $\varepsilon_{280 \mathrm{~nm}}=18887 \mathrm{M}^{-1} \mathrm{~cm}^{-1}$ and $\varepsilon_{280 \mathrm{~nm}}=26643 \mathrm{M}^{-1} \mathrm{~cm}^{-1}$, respectively, which we determined using $1 \mathrm{H}$-NMR measurements (see the online Supplementary Material).

\section{GluA2 LBD expression and purification}

The pET22b(+) plasmid encoding the GluA2 S1S2J construct (Armstrong and Gouaux, 2000) was transformed into E. coli Origami $\mathrm{B}(\mathrm{DE} 3)$. Cells were grown in $21 \mathrm{LB}$ medium supplemented with ampicillin at $37^{\circ} \mathrm{C}$ until the $\mathrm{OD}_{600}$ reached 0.8 . After addition of $100 \mu \mathrm{M}$ IPTG, protein expression was continued at $20^{\circ} \mathrm{C}$ for $20 \mathrm{~h}$. Cells were harvested by centrifugation and the fresh pellet was suspended in $30 \mathrm{ml}$ buffer A (500 mm NaCl, $20 \mathrm{~mm}$ imidazole, $20 \mathrm{~mm}$ L-Asp, $20 \mathrm{~mm}$ Tris, pH 7.4) supplemented with $1 \mathrm{~mm}$ PMSF, $0.3 \mathrm{mg} / \mathrm{ml}$ lysozyme, 3.3 U/ml DNase I, and $1 \mathrm{~mm} \mathrm{MgCl}_{2}$ at $4^{\circ} \mathrm{C}$. For cell lysis, this suspension was passed through a French press (FA-032 cell, Thermo Electron) 3 times. The following purification aimed at the GluA2 LBD contained in the soluble fraction: after centrifugation and filtration $(0.45 \mu \mathrm{m})$ the supernatant was loaded on a HisTrap HP $5 \mathrm{ml}$ column (GE Healthcare) equilibrated with buffer $\mathrm{A}$ at room temperature. After washing the column with 5 column volumes buffer A (flow rate $2 \mathrm{ml} / \mathrm{min}$ ), the concentration of buffer B (buffer A containing $500 \mathrm{~mm}$ imidazole) was increased in a step-wise fashion to elute the GluA2 LBD at $\sim 25 \%$ buffer B. Peak fractions were pooled, dialyzed 3 times against buffer C (20 mm NaCl, $1 \mathrm{~mm}$ EDTA, $10 \mathrm{~mm}$ L-Asp, $10 \mathrm{~mm}$ HEPES, pH 7.5), and then 4 times against buffer D (50 mM NaCl, $20 \mathrm{~mm}$ HEPES, $\mathrm{pH} 7.0$ ) at $4^{\circ} \mathrm{C}$ using a $3.5 \mathrm{kDa}$ MWCO regenerated cellulose membrane (SpectraPor). The purity of the His-tagged GluA2 LBD $(32.2 \mathrm{kDa})$ was confirmed by SDS-PAGE analysis and Coomassie Blue staining. Typical yields were $2 \mathrm{mg} / \mathrm{l}$ culture.

\section{Fluorescence measurements and determination of $K_{\mathrm{d}}$ values}

The GluA2 LBD was extensively dialyzed against assay buffer (50 mM $\mathrm{NaCl}, 20 \mathrm{~mm}$ HEPES, $\mathrm{pH}$ 4.5-8.0) and subjected to ultracentrifugation (135 $000 \mathrm{~g}, 30 \mathrm{~min}$ at $4^{\circ} \mathrm{C}$ ). The LBD concentration in the supernatant was determined spectroscopically with the extinction coefficient $\varepsilon_{280 \mathrm{~nm}}=41370 \mathrm{M}^{-1} \mathrm{~cm}^{-1}$ (Gasteiger et al., 2005). Fluorescence measurements were performed with $0.2 \mu \mathrm{M}$ or $0.5 \mu \mathrm{M} \mathrm{LBD}$ in $10 \times 4 \mathrm{~mm}$ quartz 
cuvettes at $20^{\circ} \mathrm{C}$ using a FluoroMax- 4 spectrofluorometer (Horiba Scientific). The excitation wavelengths were $280 \mathrm{~nm}$ or $295 \mathrm{~nm}$ and the integration time was $0.1 \mathrm{~s}$ with excitation and emission slit widths as indicated. The reported emission spectra are averages from two scans and were corrected for the corresponding buffer signal. The ligands were added to the desired final concentration using quinoxalinediones and glutamate stock solutions diluted in assay buffer. After each addition, the sample was stirred and equilibrated for $5 \mathrm{~min}$ before the first measurement was taken. Every measurement was repeated after another $10 \mathrm{~min}$ to check for sample stability. The obtained fluorescence intensity was corrected for the volume increase, which was $1 \%$ per addition.

The fraction of ligand-bound LBD was determined by analyzing the fluorescence emission intensity at $335 \mathrm{~nm}$, which is reported relative to the emission intensity of the GluA2 apo-LBD. We evaluated the data assuming a binding model with 1:1 stoichiometry, where R represents the receptor LBD and L the ligand. In this case, the dissociation constant, $K_{\mathrm{d}}$, is given by:

$$
\mathrm{R}+\mathrm{L} \leftrightharpoons \mathrm{RL} \quad K_{\mathrm{d}}=\frac{[\mathrm{R}] \cdot[\mathrm{L}]}{[\mathrm{RL}]}
$$

The general solution for the fraction of ligand-bound receptor LBDs, $\theta_{\mathrm{RL}}=[\mathrm{RL}] /[\mathrm{R}]_{0}$, is a quadratic function of $K_{\mathrm{d}}$ and the total concentrations of receptor $\mathrm{LBD},[\mathrm{R}]_{0}$, and ligand, $[\mathrm{L}]_{0}$ :

$$
\theta_{\mathrm{RL}}=\frac{[\mathrm{R}]_{0}+[\mathrm{L}]_{0}+K_{\mathrm{d}}-\sqrt{\left([\mathrm{R}]_{0}+[\mathrm{L}]_{0}+K_{\mathrm{d}}\right)^{2}-4[\mathrm{R}]_{0}[\mathrm{~L}]_{0}}}{2[\mathrm{R}]_{0}}
$$

The observed fluorescence intensity, normalized to the intensity of the apo-receptor LBD, $F\left(\left[\mathrm{~L}_{0}\right]\right) / F_{\mathrm{R}}$, is then given by:

$$
\frac{F\left([\mathrm{~L}]_{0}\right)}{F_{\mathrm{R}}}=\left(1-\theta_{\mathrm{RL}}+\theta_{\mathrm{RL}} \cdot f_{\mathrm{RL}}\right) \cdot \mathrm{e}^{-[\mathrm{L}]_{0} / \mathrm{K}_{\mathrm{IF}}}
$$

where $f_{\mathrm{RL}}=F_{\mathrm{RL}} / F_{\mathrm{R}}$ denotes the relative fluorescence intensity of the ligand-bound receptor LBD compared to the apo-LBD. To account for the apparent fluorescence decrease due to the inner filter effects caused by quinoxalinediones, we employed a correction factor with $K_{\mathrm{IF}}=(33.5 \pm 1.0) \mu \mathrm{M}$ (cf. SI and Figure S4).

The free parameters in Eq. 2, $K_{\mathrm{d}}$ and $f_{\mathrm{RL}}$ ( $\left.\mathrm{A}^{\mathrm{QX} \cdot \mathrm{LBD}}\right)$, were determined by least-square fitting to the corresponding data using the Levenberg-Marquardt algorithm implemented in ProFit 7.0 (Quantumsoft) assuming an individual error of $2 \%$ per data point.

Competition experiments were evaluated by incorporating a second ligand, A, into the same model:

$$
\mathrm{RA}+\mathrm{L} \leftrightharpoons \mathrm{R}+\mathrm{A}+\mathrm{L} \leftrightharpoons \mathrm{A}+\mathrm{RL}
$$

We used the general cubic solution (Wang, 1995) for fitting, rather than approximations, since in some cases the concentrations of ligands and LBD were close to the dissociation constants. The corresponding formulas are described as SI (Eq. S2a-h).

\section{Absorbance measurements and $\mathrm{p} K_{\mathrm{a}}$ value determination}

The protonation/deprotonation of DNQX, CNQX, NBQX and YM90K was characterized using absorbance measurements. Starting at $\mathrm{pH}$ 3.0, 30-50 $\mu \mathrm{M}$ quinoxalinedione were titrated in $20 \mathrm{ml}$ buffer (100 mm NaCl, $10 \mathrm{~mm} \mathrm{Na} \mathrm{HPO}_{4}, 10 \mathrm{~mm}$ citric acid and $10 \mathrm{~mm}$ glycine) up to $\mathrm{pH}$ 12.0. The titrant $(0.1 \mathrm{M} \mathrm{NaOH})$ was supplemented with the same concentration of quinoxalinedione to maintain a constant concentration and added in $0.1-1 \mathrm{ml}$ steps. The $\mathrm{pH}$ value was measured using a 3 м KCl glass electrode (Sentix81 WTW). Absorbance spectra were measured in a $1 \mathrm{~cm}$ quartz cuvette at room temperature using a NanoDrop 2000c spectrophotometer (Thermo Fischer Scientific).

The $\mathrm{p} K_{\mathrm{a}}$ values of DNQX and CNQX were determined assuming diprotic behavior. The observed absorbance at a given wavelength, $\mathrm{A}(\mathrm{pH})$, is then given by the $\mathrm{p} K_{\mathrm{a}}$ values, $\mathrm{p} K_{\mathrm{a}}^{1}$ and $\mathrm{p} K_{\mathrm{a}}^{2}$, describing the first and second deprotonation, respectively, and the absorbances of the species $\mathrm{A}_{\mathrm{OH} 2}, \mathrm{~A}_{\mathrm{OH}}$, and $\mathrm{A}_{\mathrm{Q} 2}$ :

$\mathrm{A}(\mathrm{pH})=\frac{1}{10^{-2 \mathrm{pH}}+10^{-\mathrm{pH}-\mathrm{pK} K_{\mathrm{a}}^{1}}+10^{-\mathrm{p} K_{\mathrm{a}}^{1}-\mathrm{pK} K_{a}^{2}}}\left(\frac{\mathrm{A}_{\mathrm{OH} 2}}{10^{2 \mathrm{pH}}}+\frac{\mathrm{A}_{\mathrm{QH}-}}{10^{\mathrm{pH}+\mathrm{p} K_{a}^{1}}}+\frac{\mathrm{A}_{\mathrm{Q} 2-}}{10^{\mathrm{p} K_{\mathrm{a}}^{1}+\mathrm{pK} K_{\mathrm{a}}^{2}}}\right)$

All $\mathrm{p} K_{\mathrm{a}}$ values were determined by simultaneous fitting of the absorbance changes at multiple wavelengths that were representative of the various transitions (cf. Figure S5-7). Least-square minimization was performed using the Levenberg-Marquardt algorithm implemented in ProFit 7.0 (Quantumsoft). The corresponding equation for analyzing the data obtained for NBQX, which carries a third protonation site, is given as online supplementary information.

\section{Analysis of thermodynamic coupling}

The analysis of the coupled deprotonation/protonation and binding/ unbinding equilibrium (Figure 5A) assumes that only the ligand undergoes a single deprotonation in the investigated $\mathrm{pH}$ range, whereas the LBD is not affected by $\mathrm{pH}$, for details see the supplementary material. Non-linear least-square fitting of data points was performed using Eq. 1 assuming individual errors of $15 \%$ for the data points.

Acknowledgments: We thank E. Gouaux (Vollum Institute, Oregon Health \& Science University, Portland, OR, USA) for sharing the GluA2 S1S2J expression plasmid and we thank Daniel Tapken and Felix Borowski for advice on protein purification. The project was founded by a grant of the NRW-Rückkehrerprogramm (A.R). Access to NMR instrumentation was provided by the RUBiospek facility.

\section{References}

Abele, R., Keinänen, K., and Madden, D.R. (2000). Agonist-induced isomerization in a glutamate receptor ligand-binding domain. A kinetic and mutagenetic analysis. J. Biol. Chem. 275, 21355-21363.

Ahmed, A.H., Thompson, M.D., Fenwick, M.K., Romero, B., Loh, A.P., Jane, D.E., Sondermann, H., and Oswald, R.E. (2009). Mechanisms of antagonism of the GluR2 AMPA receptor: structure and dynamics of the complex of two willardiine antagonists with the glutamate binding domain. Biochemistry 48, 3894-3903.

Andersen, P.H., Tygesen, C.K., Rasmussen, J.S., Søegaard-Nielsen, L., Hansen, A., Hansen, K., Kiemer, A., and Stidsen, C.E. (1996). Stable expression of homomeric AMPA-selective glutamate receptors in BHK cells. Eur. J. Pharmacol. 311, 95-100. 
Armstrong, N. and Gouaux, E. (2000). Mechanisms for activation and antagonism of an AMPA-sensitive glutamate receptor: crystal structures of the GluR2 ligand binding core. Neuron 28 , 165-181.

Armstrong, N., Sun, Y., Chen, G.Q., and Gouaux, E. (1998). Structure of a glutamate-receptor ligand-binding core in complex with kainate. Nature 395, 913-917.

Barber, D.M., Liu, S.A., Gottschling, K., Sumser, M., Hollmann, M., and Trauner, D. (2017). Optical control of AMPA receptors using a photoswitchable quinoxaline-2,3-dione antagonist. Chem. Sci. 8, 611-615.

Biscoe, T.J., Evans, R.H., Francis, A.A., Martin, M.R., Watkins, J.C., Davies, J., and Dray, A. (1977). D- $\alpha$-aminoadipate as a selective antagonist of amino acid-induced and synaptic excitation of mammalian spinal neurones. Nature 270, 743-745.

Chen, G.Q. and Gouaux, E. (1997). Overexpression of a glutamate receptor (GluR2) ligand binding domain in Escherichia coli: application of a novel protein folding screen. Proc. Natl. Acad. Sci. USA 94, 13431-13436.

Cordi, A.A., Desos, P., Randle, J.C., and Lepagnol, J. (1995). Structure-activity relationships in a series of 3-sulfonylamino-2-(1H)quinolones, as new AMPA/kainate and glycine antagonists. Bioorg. Med. Chem. 3, 129-141.

Cruz, L.A., Estébanez-Perpiñá, E., Pfaff, S., Borngraeber, S., Bao, N., Blethrow, J., Fletterick, R.J., and England, P.M. (2008). 6-Azido7-nitro-1,4-dihydroquinoxaline-2,3-dione (ANQX) forms an irreversible bond to the active site of the GluR2 AMPA receptor. J. Med. Chem. 51, 5856-5860.

De Freitas, G.R.S., Coelho, S.E., Monteiro, N.K.V., Neri, J.M., Cavalcanti, L.N., Domingos, J.B., Vieira, D.S., de Souza, M.A.F., and Menezes, F.G. (2017). Theoretical and experimental investigation of acidity of the glutamate receptor antagonist 6,7-dinitro1,4-dihydroquinoxaline-2,3-dione and its possible implication in GluA2 binding. J. Phys. Chem. A 121, 7414-7423.

Deming, D., Cheng, Q., and Jayaraman, V. (2003). Is the isolated ligand binding domain a good model of the domain in the native receptor? J. Biol. Chem. 278, 17589-17592.

Demmer, C.S., Møller, C., Brown, P.M., Han, L., Pickering, D.S., Nielsen, B., Bowie, D., Frydenvang, K., Kastrup, J.S., and Bunch, L. (2015). Binding mode of an $\alpha$-amino acid-linked quinoxaline-2,3-dione analogue at glutamate receptor subtype GluK1. ACS Chem. Neurosci. 6, 845-854.

Demmer, C.S., Rombach, D., Liu, N., Nielsen, B., Pickering, D.S., and Bunch, L. (2017). Revisiting the quinoxalinedione scaffold in the construction of new ligands for the ionotropic glutamate receptors. ACS Chem. Neurosci. 8, 2477-2495.

Elting, J.W., Sulter, G.A., Kaste, M., Lees, K.R., Diener, H.C., Hommel, M., Versavel, M., Teelken, A.W., and De Keyser, J. (2002). AMPA antagonist ZK200775 in patients with acute ischemic stroke: possible glial cell toxicity detected by monitoring of S-100B serum levels. Stroke 33, 2813-2818.

Gasteiger, E., Hoogland, C., Gattiker, A., Duvaud, S., Wilkins, M.R., Appel, R.D., and Bairoch, A. (2005). Protein identification and analysis tools on the ExPASy Server. In: The Proteomics Protocols Handbook, J.M. Walker, ed. (Humana Press).

Heinzelmann, G., Chen, P.C., and Kuyucak, S. (2014). Computation of standard binding free energies of polar and charged ligands to the glutamate receptor GluA2. J. Phys. Chem. B. 118, 1813-1824.

Holley, S.M., Ahmed, A.H., Srinivasan, J., Murthy, S.E., Weiland, G.A., Oswald, R.E., and Nowak, L.M. (2012). The loss of an electro- static contact unique to AMPA receptor ligand binding domain 2 slows channel activation. Biochemistry 51, 4015-4027.

Hollmann, M., O'Shea-Greenfield, A., Rogers, S.W., and Heinemann, S. (1989). Cloning by functional expression of a member of the glutamate receptor family. Nature 342, 643-648.

Honoré, T., Davies, S.N., Drejer, J., Fletcher, E.J., Jacobsen, P., Lodge, D., and Nielsen, F.E. (1988). Quinoxalinediones: potent competitive non-NMDA glutamate receptor antagonists. Science 241, 701-703.

Keana, J.F., Kher, S.M., Cai, S.X., Dinsmore, C.M., Glenn, A.G., Guastella, J., Huang, J.C., Ilyin, V., Lü, Y., and Mouser, P.L. (1995). Synthesis and structure-activity relationships of substituted 1,4-dihydroquinoxaline-2,3-diones: antagonists of $\mathrm{N}$-methylD-aspartate (NMDA) receptor glycine sites and non-NMDA glutamate receptors. J. Med. Chem. 38, 4367-4379.

Keinänen, K., Wisden, W., Sommer, B., Werner, P., Herb, A., Verdoorn, T.A., Sakmann, B., and Seeburg, P.H. (1990). A family of AMPA-selective glutamate receptors. Science 249, 556-560.

Klein, R.M. and Howe, J.R. (2004). Effects of the Lurcher mutation on GluR1 desensitization and activation kinetics. J. Neurosci. 24, 4941-4951.

Krishnamurthy, M., Iyer, K.A., and Dogra, S.K. (1987). Electronic structure of quinoxaline-2,3(1H,4H)dione and its prototropic species in the ground and excited singlet states. J. Photochem. 38, 277-287.

Lai, T.W., Zhang, S., and Wang, Y.T. (2014). Excitotoxicity and stroke: identifying novel targets for neuroprotection. Prog. Neurobiol. 115, 157-188.

Larsen, A.M. and Bunch, L. (2011). Medicinal chemistry of competitive kainate receptor antagonists. ACS Chem. Neurosci. 2, 60-74.

Madden, D.R., Thiran, S., Zimmermann, H., Romm, J., and Jayaraman, V. (2001). Stereochemistry of quinoxaline antagonist binding to a glutamate receptor investigated by Fourier transform infrared spectroscopy. J. Biol. Chem. 276, 37821-37826.

Mah, S.J., Cornell, E., Mitchell, N.A., and Fleck, M.W. (2005). Glutamate receptor trafficking: endoplasmic reticulum quality control involves ligand binding and receptor function. J. Neurosci. 25, 2215-2225.

Martinez, M., Ahmed, A.H., Loh, A.P., and Oswald, R.E. (2014). Thermodynamics and mechanism of the interaction of willardiine partial agonists with a glutamate receptor: implications for drug development. Biochemistry 53, 3790-3795.

Menuz, K., Stroud, R.M., Nicoll, R.A., and Hays, F.A. (2007). TARP auxiliary subunits switch AMPA receptor antagonists into partial agonists. Science 318, 815-817.

Mott, D.D., Washburn, M.S., Zhang, S., and Dingledine, R.J. (2003). Subunit-dependent modulation of kainate receptors by extracellular protons and polyamines. J. Neurosci. 23, 1179-1188.

Niswender, C.M. and Conn, P.J. (2010). Metabotropic glutamate receptors: Physiology, pharmacology, and disease. Annu. Rev. Pharmacol. Toxicol. 50, 295-322.

Ohmori, J., Sakamoto, S., Kubota, H., Shimizu-Sasamata, M., Okada, M., Kawasaki, S., Hidaka, K., Togami, J., Furuya, T., and Murase, K. (1994). 6-(1H-imidazol-1-yl)-7-nitro-2,3(1H,4H)-quinoxalinedione hydrochloride (YM90K) and related compounds: structureactivity relationships for the AMPA-type non-NMDA receptor. J. Med. Chem. 37, 467-475.

Petrik, A.F., Strub, M.P., and Lee, J.C. (2010). Energy transfer ligands of the GluR2 ligand binding core. Biochemistry 49, 2051-2057. 
Poulie, C.B. and Bunch, L. (2013). Heterocycles as nonclassical bioisosteres of $\alpha$-amino acids. ChemMedChem. 8, 205-215.

Pøhlsgaard, J., Frydenvang, K., Madsen, U., and Kastrup, J.S. (2011). Lessons from more than 80 structures of the GluA2 ligandbinding domain in complex with agonists, antagonists and allosteric modulators. Neuropharmacology 60, 135-150.

Reiner, A. and Isacoff, E.Y. (2014). Tethered ligands reveal glutamate receptor desensitization depends on subunit occupancy. Nat. Chem. Biol. 10, 273-280.

Reiner, A. and Levitz, J. (2018). Glutamatergic signaling in the central nervous system: ionotropic and metabotropic receptors in concert. Neuron 98, 1080-1098.

Rogawski, M.A. (2013). AMPA receptors as a molecular target in epilepsy therapy. Acta Neurol. Scand. 127, 9-18.

Rosenmund, C., Stern-Bach, Y., and Stevens, C.F. (1998). The tetrameric structure of a glutamate receptor channel. Science 280 , 1596-1599.

Sheardown, M.J., Nielsen, E.O., Hansen, A.J., Jacobsen, P., and Honoré, T. (1990). 2,3-Dihydroxy-6-nitro-7-sulfamoyl-benzo(F) quinoxaline: a neuroprotectant for cerebral ischemia. Science 247, 571-574.

Sobolevsky, A.I., Rosconi, M.P., and Gouaux, E. (2009). X-ray structure, symmetry and mechanism of an AMPA-subtype glutamate receptor. Nature 462, 745-756.

Stern-Bach, Y., Bettler, B., Hartley, M., Sheppard, P.O., O'Hara, P.J., and Heinemann, S.F. (1994). Agonist selectivity of glutamate receptors is specified by two domains structurally related to bacterial amino acid-binding proteins. Neuron 13 , 1345-1357.

Sun, P.Z., Wang, E., and Cheung, J.S. (2012). Imaging acute ischemic tissue acidosis with $\mathrm{pH}$-sensitive endogenous amide proton transfer (APT) MRI-correction of tissue relaxation and concomitant RF irradiation effects toward mapping quantitative cerebral tissue $\mathrm{pH}$. Neuroimage 60,1-6.

Swanson, G.T., Gereau, R.W., Green, T., and Heinemann, S.F. (1997). Identification of amino acid residues that control functional behavior in GluR5 and GluR6 kainate receptors. Neuron 19, 913-926.

Takahashi, M., Kohara, A., Shishikura, J., Kawasaki-Yatsugi, S., Ni, J.W., Yatsugi, S., Sakamoto, S., Okada, M., Shimizu-

Sasamata, M., and Yamaguchi, T. (2002). YM872: a selective, potent and highly water-soluble $\alpha$-amino-3-hydroxy-5methylisoxazole-4-propionic acid receptor antagonist. CNS Drug. Rev. 8, 337-352.

Tang, C.M., Dichter, M., and Morad, M. (1990). Modulation of the $\mathrm{N}$-methyl-D-aspartate channel by extracellular $\mathrm{H}^{+}$. Proc. Natl. Acad. Sci. USA 87, 6445-6449.
Taverna, F., Xiong, Z.G., Brandes, L., Roder, J.C., Salter, M.W., and MacDonald, J.F. (2000). The Lurcher mutation of an $\alpha$-amino-3hydroxy-5-methyl-4-isoxazolepropionic acid receptor subunit enhances potency of glutamate and converts an antagonist to an agonist. J. Biol. Chem. 275, 8475-8479.

Traynelis, S.F. and Cull-Candy, S.G. (1991). Pharmacological properties and $\mathrm{H}^{+}$sensitivity of excitatory amino acid receptor channels in rat cerebellar granule neurones. J. Physiol. 433, 727-763.

Traynelis, S.F., Wollmuth, L.P., McBain, C.J., Menniti, F.S., Vance, K.M., Ogden, K.K., Hansen, K.B., Yuan, H., Myers, S.J., and Dingledine, R. (2010). Glutamate receptor ion channels: structure, regulation, and function. Pharmacol. Rev. 62, 405-496.

Turski, L., Huth, A., Sheardown, M., McDonald, F., Neuhaus, R., Schneider, H.H., Dirnagl, U., Wiegand, F., Jacobsen, P., and Ottow, E. (1998). ZK200775: a phosphonate quinoxalinedione AMPA antagonist for neuroprotection in stroke and trauma. Proc. Natl. Acad. Sci. USA 95, 10960-10965.

Uchino, S., Sakimura, K., Nagahari, K., and Mishina, M. (1992). Mutations in a putative agonist binding region of the AMPAselective glutamate receptor channel. FEBS Lett. 308, 253-257.

Vyklický, L., Vlachová, V., and Krůsek, J. (1990). The effect of external $\mathrm{pH}$ changes on responses to excitatory amino acids in mouse hippocampal neurones. J. Physiol. 430, 497-517.

Wafford, K.A., Kathoria, M., Bain, C.J., Marshall, G., Le Bourdellès, B., Kemp, J.A., and Whiting, P.J. (1995). Identification of amino acids in the $N$-methyl-D-aspartate receptor NR1 subunit that contribute to the glycine binding site. Mol. Pharmacol. 47, 374-380.

Wang, Z.X. (1995). An exact mathematical expression for describing competitive binding of two different ligands to a protein molecule. FEBS Lett. 360, 111-114.

Weston, M.C., Gertler, C., Mayer, M.L., and Rosenmund, C. (2006). Interdomain interactions in AMPA and kainate receptors regulate affinity for glutamate. J. Neurosci. 26, 7650-7658.

Xie, D., Wang, Y., Xie, J., Lu, J., Cui, J., Zhang, M., Fu, L., and Wang, Y. (2014). Quinoxaline-2,3-diones: potential D-amino acid oxidase (DAAO) inhibitors. Med. Chem. Res. 23, 4977-4989.

Yao, Y. and Mayer, M.L. (2006). Characterization of a soluble ligand binding domain of the NMDA receptor regulatory subunit NR3A. J. Neurosci. 26, 4559-4566.

Yu, A., Salazar, H., Plested, A.J.R., and Lau, A.Y. (2018). Neurotransmitter funneling optimizes glutamate receptor kinetics. Neuron 97, 139-149.

Supplementary Material: The online version of this article offers supplementary material (https://doi.org/10.1515/hsz-2018-0464). 